\title{
Assessment of Building Resistance to Accidental Actions in the Social Aspect of Sustainable Construction
}

\author{
Aleksandra Radziejowska ${ }^{1}$ and Anna Sobotka ${ }^{2}$ \\ ${ }^{1}$ AGH University of Science and Technology in Cracow, Faculty of Mining \\ and Geoengineering, Av. Mickiewicza 30, 30-059 Cracow, Poland, e-mail: aradziej@agh.edu.pl \\ ${ }^{2}$ AGH University of Science and Technology in Cracow, Faculty of Mining \\ and Geoengineering, Av. Mickiewicza 30,30-059 Cracow, Poland, e-mail: sobotka@agh.edu.pl
}

\begin{abstract}
In the article is considered one of the categories of social aspect of sustainable construction as specified in the standard EN 16309:2014 - namely: safety and security. The authors analyzed the component of the above-mentioned category with a subcategory called: resistance of buildings for accidental actions. The assessment criteria are: earthquake resistance, explosion resistance, fire performance and traffic impacts. A model of building's assessment of random interactions is presented, which will allow to make comparisons of the object's safety in the investigated ranges with other residential buildings, as well as with a reference building.
\end{abstract}

Keywords: Social Aspect, Security and Safety, Sustainable Construction, Accidental Actions.

\section{Introduction}

Civil engineering is one of the main branches of the economy in which the goals of sustainable development are realized. According to (ISO 15392, 2008), three main aspects have been identified in sustainable construction: environmental, social and economic. Due to a number of studies and publications related to both the environmental and economic aspects, the authors focused on finding a model for assessing the social aspect, which is important for the user's comfort and health, especially in residential buildings (Yılmaz and Bakış, 2015).

Assessing the social aspect of a building is a difficult process. Only part of the assessed elements of the considered criteria can be quantified, compared with the parameters specified in legal acts and standards. On the other hand, such assessment allows to determine whether the object meets the examined criteria, thus allowing to obtain information about the facility's ability to meet the needs and expectations of users.

In this study, one of the subcategories of the sixth category $\left(K_{6}\right)$ of social assessment regarding safety and security will be discussed and developed. Category $K_{6}$ Safety and security consists of four subcategories, which include: $K_{61}$ Resistance to climate change, $K_{62}$ Safety and security against accidental actions, $K_{63}$ Safety and security against intruders and vandalism and $K_{64}$ Security against interruptions of utility supply (EN 15643-1, 2011), (EN 15643-3, 2012). The subgroup that the authors presents concerns on $K_{62}$ Safety and security against accidental actions, which consists of four criteria that will be included in the proposed assessment: $K_{621}$ Earthquake (rockburst mining), $K_{622}$ Explosions, $K_{623}$ Fire resistance and $K_{624}$ Resistance to dynamic external actions (Fig. 1). This publication is part of the work, which aims to present a comprehensive method of assessing the social aspect of sustainable construction. 


\section{Subcategory $K_{62}$ Safety and Security Against Accidental Actions}

The safety and security category is a measure of the building's ability to withstand current and future anticipated loads such as: rain, strong wind, snow, flood, fire, earthquake, explosion, landslide, etc., as well as protection against vandalism and crime and safety during use. It is a measure of the ability of buildings to provide safe shelter during exceptional events that may affect user safety.

In random impacts is assed building resistance (protection / forces / deformation / stability and safety) against accidental loads resulting from one-off events, e.g. earthquakes, explosions, fire and traffic, and their secondary effects (e.g. projectiles, toxic gases, crushed glass, etc.).

Figure 1 shows the division of the subcategory Safety and security against accidental actions $\left(K_{62}\right)$, which is a component characterizing the Safety and security $\left(K_{6}\right)$ category (EN 16309, $2014+\mathrm{A} 1) . K_{62}$ is assessed by the criteria marked later in the article by the symbols $K_{621} \div K_{624}$. For the assessment of the criteria a discrete five-point scale was adonted, in which the most advantageous solution will assume the highest value equal to 5 (Radziejowska, 2018).
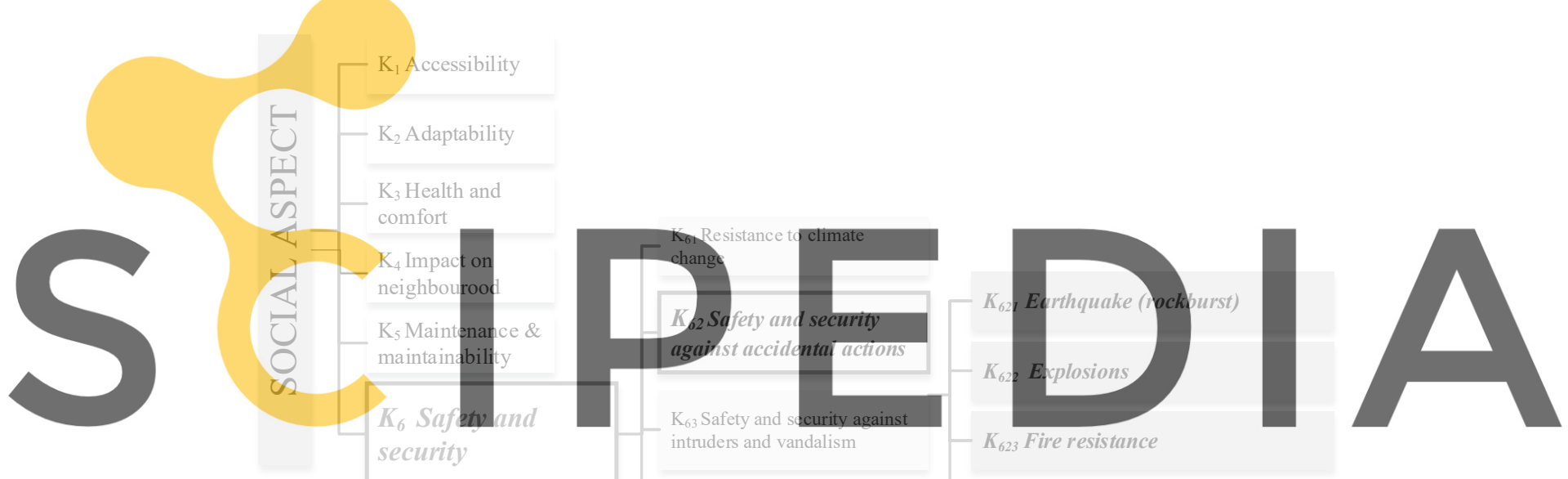

Register for free at https//www.scipediakcomitodownload thesversionuwithout the watermark

Figure 1. Fragment of the base structure of the criteria included in the proposed assessment (own elaboration).

\section{Determining the Method of Evaluation of the Criteria}

\subsection{Determining the Scale of Parameter Values Characterizing the Criterion $K_{621}$}

Criterion $K_{621}$ Earthquake resistance; rockburst mining should be assessed through the use of protective measures in the building, which can be implemented by increasing structural stability, assembly of elements ensuring flexibility and shock resistance, resistant to breaking glass or alarm systems and gas and water shut-off valves.

Poland is located outside the areas of active tectonic plates, it is classified as aseismic zone. The specificity of our country, and more specifically the areas of mining basins, is the occurrence of paraseismic shocks, which are a consequence of underground mining operations. The phenomenon during which rapid destruction of the rock structure surrounding the excavation occurs as a result of exceeding their strength is called rockburst. The effect of such 
a dynamic phenomenon in the rock mass (rapid rock relaxation) is the emission of vibrations, i.e. the seismic shock effect. Shock (seismic) waves propagate to the surface, which induce vibrations of buildings (Fig. $2 \& 3$ ).

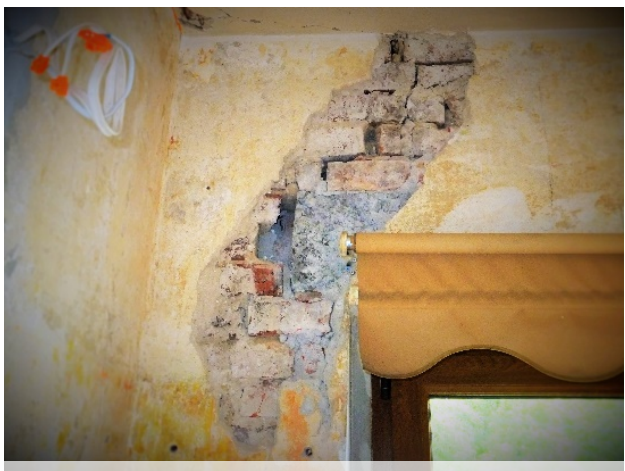

Figure 2. Cracks formed in a residential building in post-mining areas, around Bytom in Poland, 22/05/2011.

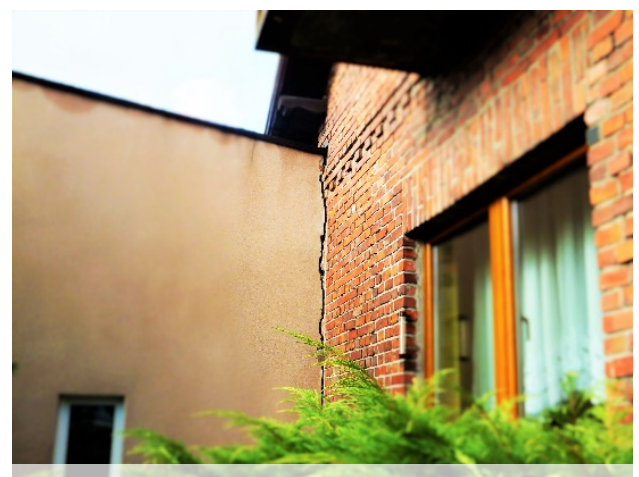

Figure 3. The uncontrolled dilatation of the building was created as a result of post-mining burst, around Bytom, 22/05/2011

At the Central Mining Institute has been developed so-called Mining Scale of Intensity (Barański, 2014) for the area of the Upper Silesian Coalfield, based on the correlation of observed effects in buildings with the values of vibration parameters - so this is an empirical scale. The shock parameters necessary to assess the degree of vibration intensity on the surface for the GSIGZWKW-2012 scale are: the amplitude of the vibration speed and their duration
Based on the existing GSIGZWKW-2012 sdale, concerning the level of nuisance and related
technical requirements necessary to be implemented shall be assessed the building's resistance
to earthquakes (rock bursts) - criterion $\mathrm{K}_{621}$ - depending on the determined shocks according
to a 5-point scale with levels with the following meaning: 5 - imperceptible nuisance, 4 -low nuisance, 3 - medium nuisance, 2 - high nuisance, 1 - very high nuisance (Table 1).

Register for free at https//www.scipedia.com to download the version without the watermark Table 1. Assessment of building resistance depending on the established level of nuisance and technical requirements for objects located in mining areas.

\begin{tabular}{|c|c|c|c|c|c|c|}
\hline \multirow{2}{*}{$\begin{array}{c}\text { Scale of } \\
\text { evaluation }\end{array}$} & \multicolumn{5}{|c|}{ Nuisance level } & \multirow{2}{*}{$\begin{array}{c}\text { Technical } \\
\text { requirements fulfilled }\end{array}$} \\
\hline & Level 0 & Level I & Level II & Level III & Level IV & \\
\hline 5 & \multicolumn{6}{|c|}{ Fulfilled technical requirements for the considered level } \\
\hline 4 & & $\bar{X}$ & & & & - \\
\hline 3 & & & $\mathrm{X}$ & & & - \\
\hline 2 & & & & $\mathrm{X}$ & & - \\
\hline 1 & & & & & $\mathrm{X}$ & - \\
\hline
\end{tabular}

\subsection{Determining the Scale of Parameter Values Characterizing the Criterion $\boldsymbol{K}_{622}$}

Criterion $K_{622}$ Explosions, similarly to the previous one should be assessed by the applied protective measures or avoiding the use of explosive gases in buildings, installation of breakproof glass and separation of shelters inside 
During the operation of residential buildings, there are two causes of disasters caused by explosions:

- gas explosion

- terrorist attack.

Construction disasters caused by an explosion are not common events, however, the consequences they carry are disproportionately high (Koccaz, Fatih Sutcu i Torunbalci, 2008).

In both causes of explosions in buildings, the method of protection should be similar and consist of the use of solutions that increase the building's resistance in this type of threat (Table 2).

Table 2. Assessment of residential buildings resistance to explosions.

\begin{tabular}{|c|c|c|c|c|c|c|c|}
\hline \multirow[b]{2}{*}{ Scale } & \multicolumn{2}{|c|}{ Wired gas } & \multicolumn{2}{|c|}{ Propane-butane gas } & \multirow{2}{*}{$\begin{array}{c}\text { Gas } \\
\text { detectors }\end{array}$} & \multicolumn{2}{|c|}{ Construction } \\
\hline & with valve & without & with valve & without & & resistant & no \\
\hline 5 & + & & & & + & + & \\
\hline & + & & & & + & & + \\
\hline 4 & & & + & & + & + & \\
\hline 3 & & + & & & + & & \\
\hline 2 & & & + & & & & + \\
\hline 1 & & & & + & & & + \\
\hline
\end{tabular}

elements, improve access for fire brigades, make evacuation routes taking into account the

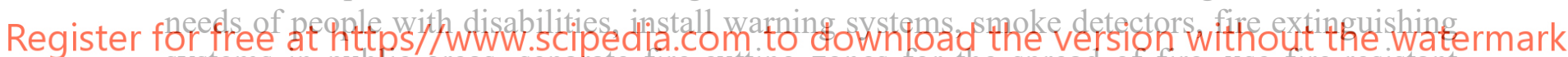
systems in public areas, separate fire-cutting zones for the spread of fire, use fire-resistant products in places most exposed to fire (Fig. 4) (Phan, McAllister i Gross, 2010).

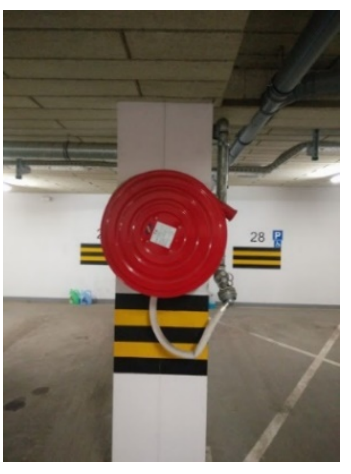

Figure 4. Fire extinguisher placed in the underground garage of a multi-family building $02 / 02 / 2016$.

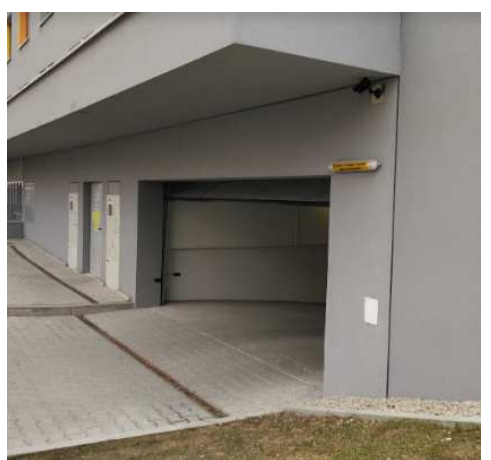

Figure 5. Entrance to the underground garage with a display informing about the concentration of carbon monoxide 12/06/2016.

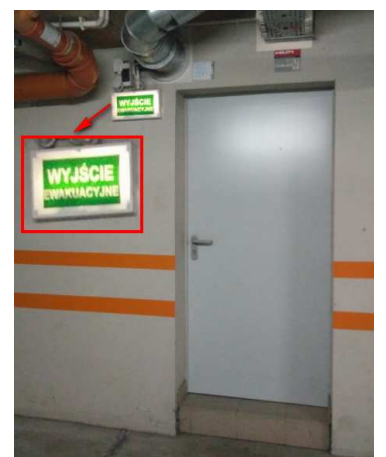

Figure 6. Emergency exit from the underground garage in a residential building 11/10/2016.

An important element is also the users' awareness of the measures used in the event of 
random events, which should be implemented by e.g. placing appropriate instructions in the common parts regarding evacuation or operating instructions for the use of fire-fighting equipment (Fig. 5\&6).

For the assessment of Fire safety - criterion $K_{623}$ - depending on the established safeguards, as in previous, a five-degree discrete scale was adopted, as is shown in Table 3.

Table 3. Fire safety assessment of buildings $\boldsymbol{K}_{\mathbf{6 2 3}}$.

\begin{tabular}{|c|c|c|c|c|c|}
\hline \multirow[b]{2}{*}{ Scale } & \multicolumn{5}{|c|}{ The degree of compliance with the requirements according to the Table 3} \\
\hline & All 5 met & $\begin{array}{l}4+1 \text { met to a } \\
\text { limited extent }\end{array}$ & $\begin{array}{l}3+2 \text { met to a } \\
\text { limited extent }\end{array}$ & $\begin{array}{l}2+3 \text { met to a } \\
\text { limited extent }\end{array}$ & $\begin{array}{l}1+4 \text { met to a } \\
\text { limited extent }\end{array}$ \\
\hline 5 & + & & & & \\
\hline 4 & & + & & & \\
\hline 3 & & & + & & \\
\hline 2 & & & & + & \\
\hline 1 & & & & & + \\
\hline
\end{tabular}

\section{Where the requirements are:}

The proper load-bearing capacity of the structure in a timely manner after the fire

Limiting the spread of fire and smoke in the building

Limiting the spread of fire to neighboring buildings

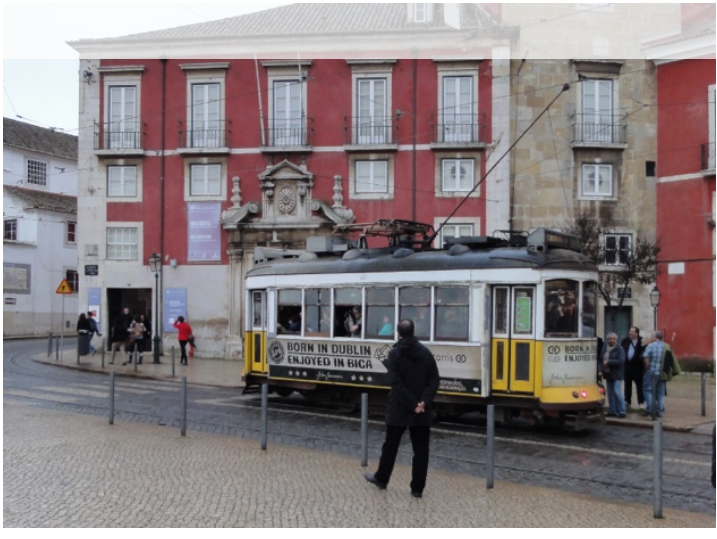

Figure 7. Tram line running right next to multifamily buildings, Lisbon 31/12/2015.

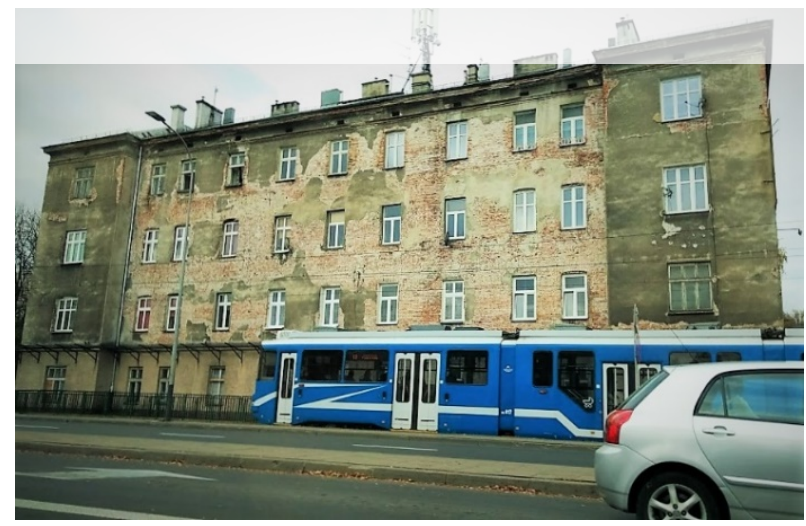

Figure 8. Tram line and busy two-lane road in the Borek Fałęcki district in Krakow, 25/10/2016.

After consultation with an expert in the field of the impact of vibrations on people and buildings, it was assumed that the assessment of criterion $K_{624}$ should be carried out separately 
for both sub-criteria: The impact of vibrations on people (Table 4) i Impact of vibration on buildings (Table 5). It was determined that the final value less favorable from both grades obtained will be adopted.

Table 4. The impact of vibrations on people.

\begin{tabular}{|c|c|c|c|c|c|c|}
\hline Scale & $\begin{array}{l}a<a_{d o p} \text { for } \\
\text { direction } x \& y\end{array}$ & $\begin{array}{l}a<a_{\text {dop }} \text { for } \\
\text { direction } z\end{array}$ & $\begin{array}{l}a=a_{d o p} \text { for } \\
\text { direction } x \& y\end{array}$ & $\begin{array}{l}a=a_{\text {dop }} \text { for } \\
\text { direction } z\end{array}$ & $\begin{array}{l}a<a_{d o p} \text { dla for } \\
\text { direction } x \& y\end{array}$ & $\begin{array}{l}a<a_{d o p} \text { for } \\
\text { direction } z\end{array}$ \\
\hline 5 & + & + & & & & \\
\hline \multirow{2}{*}{4} & & + & + & & & \\
\hline & + & & & + & & \\
\hline 3 & & & + & + & & \\
\hline \multirow{2}{*}{2} & & & & + & + & \\
\hline & & & + & & & + \\
\hline 1 & & & & & + & + \\
\hline
\end{tabular}

\section{where:}

$a_{\text {dop }}$ - limit values for vibration acceleration

Assessment of the impact of vibration transmitted through the ground to buildings, depending on the determined vibration results, a discrete five-degree scale with levels was adopted with the following meaning:

\section{5 - imperceptible vibrations, \\ 4 - noticeable but harmless, \\ - harmful, \\ 2 - highly harmful (danger to}

1 - causing building failure.
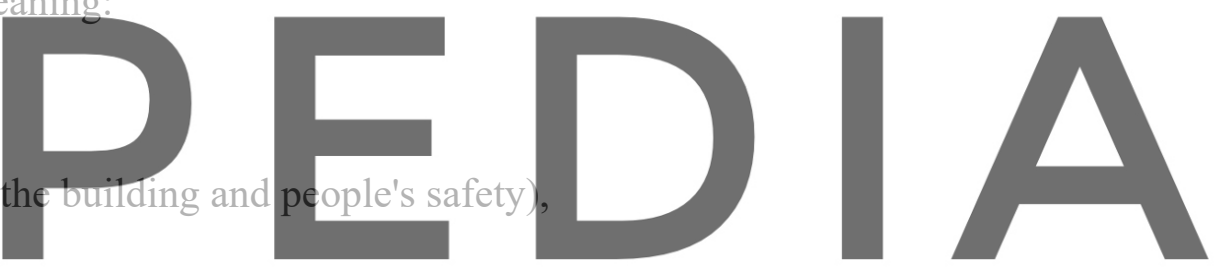

Register for free at https//www.scipedia.com to download the version without the watermark

\begin{tabular}{|c|c|c|c|c|c|}
\multirow{2}{*}{ Scale } & \multicolumn{5}{|c|}{ Impact of vibration on buildings } \\
\cline { 2 - 6 } & Zone I & Zone II & Zone III & Zone IV & Zone V \\
\hline $\mathbf{5}$ & + & & & & \\
\hline $\mathbf{4}$ & & + & & & \\
\hline $\mathbf{3}$ & & & + & + & \\
\hline $\mathbf{2}$ & & & & & + \\
\hline $\mathbf{1}$ & & & & & \\
\hline
\end{tabular}

\section{A Method Proposal for Assessing Building Resistance to Random Influences}

The authors while developing the classes of standards in the assessed criteria for selected categories used, among others:

- national standards and regulations on technical conditions to be met by buildings and their location,

- expert research,

- direct surveys conducted among users, 
- in situ research.

The proposed method assesses both quantitative and qualitative features. Qualitative features had to be processed into quantitative form by using the appropriate mathematical apparatus, e.g. fuzzy sets. Then all values were processed into non-denominated values, finally all criteria are evaluated using a discrete 5-point Likert scale, which allows comparison of features that were initially found in different physical measures. In addition, developing a method for quantifying grades required determining the weighting of the criteria. The final characteristics of the selected subcategory of the social aspect of the building is expressed in the form of a scalar function taking into account the weight of each criterion.

The vector below characterizes the subcategory $\left(K_{62}\right.$ Safety and security against accidental actions) of the social aspect together with the matrix of weights assigned to it.

$$
\begin{aligned}
O_{2 j}^{6} & =\left[\begin{array}{llll}
o_{2,1}^{6} & o_{2,2}^{6} & o_{2,3}^{6} & o_{2,4}^{6}
\end{array}\right] \\
\Lambda_{2 j}^{6} & =\left[\begin{array}{llll}
\lambda_{2,1}^{6} & \lambda_{2,2}^{6} & \lambda_{2,3}^{6} & \lambda_{2,4}^{6}
\end{array}\right]
\end{aligned}
$$

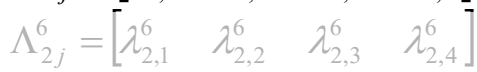

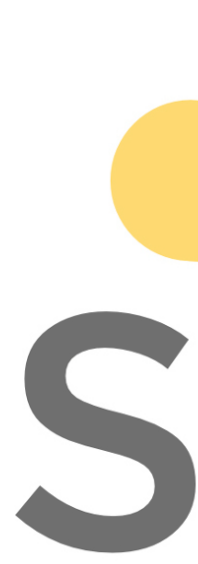

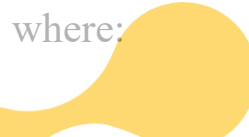

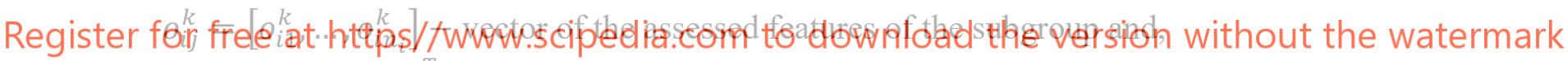

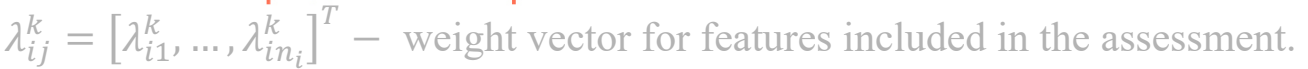

The above calculations should be made for the tested building as well as for the reference building. The reference building (reference building) will be treated as a hypothetical building designed in accordance with applicable standards and common practice and having the same technological, construction and functional parameters as the building being assessed. The reference building is to be used for carrying out comparative calculations with the analyzed object (Owczarek, 2006) .

The obtained values should be compared with the assessment obtained by the reference object, which will allow to assess how well the examined object is assessed in the scope of this subcategory. The information obtained from the calculations will indicate the weakest features that the analyzed building has, which will allow it to take appropriate action in the refurbishment policy in the future (Radziejowska, 2018).

\section{Conclusions}

The method of standardizing subcategory evaluations proposed in the work on the example of 
$\mathrm{K}_{62}$ is a contribution to the unification of the assessment of social performance of sustainable construction. The established threshold values, the adopted scale of assessments for the considered criteria, as well as the weights assigned to individual criteria and subcategories are largely based on expert research.

The presented method of assessing the social aspect of sustainable construction based on the example of subcategory $\mathrm{K}_{62}$ allows to make a comparison regarding the building's resistance to random events between the tested building and the reference object, as well as between buildings made in different technologies. In the longer term, it will determine the scope of the planned refurbishment of the building, and may also be helpful in valuing the property.

\section{Acknowledgements}

The work was carried out as part of statutory research no. 11.11.100.197 in the Department of Geomechanics, Civil Engineering and Geotechnics of Faculty of Mining and Geoengineering, AGH University of Science and Technology in Cracow.

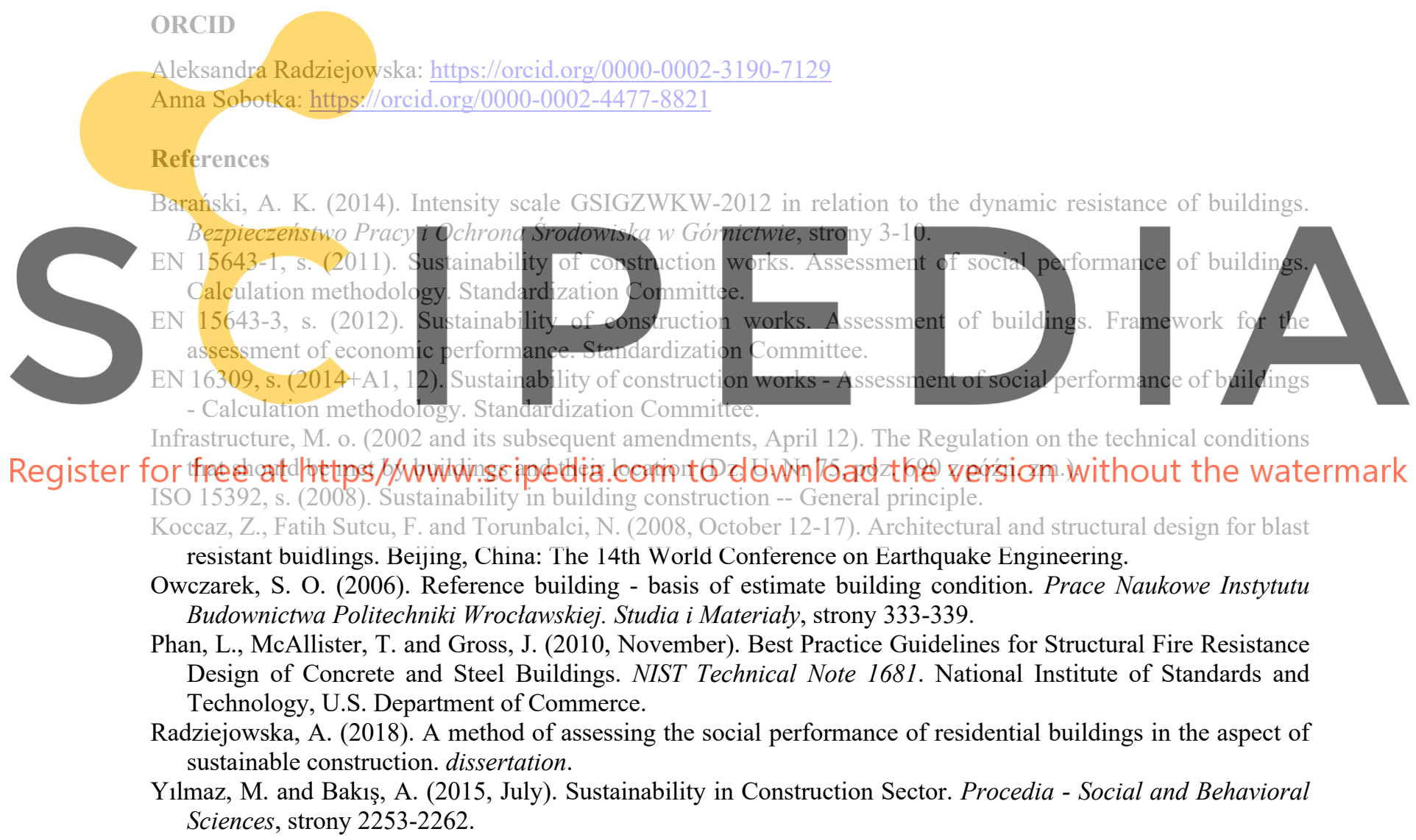

